\title{
Glutamine Metabolism in Nitrogen-starved Conidia of Neurospora crassa
}

\author{
By GUADALUPE ESPÍN, RAFAEL PALACIOS AND JAIME MORA \\ Departamento de Biología Molecular, Instituto de Investigaciones Biomédicas, \\ Universidad Nacional Autónoma de México, Apdo Postal 70228, \\ México 20, D.F., Mexico
}

(Received 21 February 1979)

\begin{abstract}
During nitrogen deprivation, de novo synthesis of glutamine synthetase was induced in nongrowing conidia of Neurospora crassa. When ammonia or glutamine was added to conidia which had been deprived of nitrogen, glutamine and arginine accumulated at a higher rate than in condia not deprived of nitrogen. The degradation of exogenous glutamine to glutamate is apparently a necessary step in the accumulation of glutamine and arginine within the conidia. In non-growing conidia, a cycle probably operates in which glutamine is degraded and resynthesized. The advantages of such a cycle would be that the carbon and nitrogen could be used to synthesize amino acids in general, as well as for the synthesis and accumulation of arginine and/or glutamine in particular.
\end{abstract}

\section{INTRODUCTION}

Conidia of Neurospora crassa accumulate glutamine and arginine under conditions of amino acid deprivation. This accumulation requires a supply of carbon and nitrogen sources, an intact arginine biosynthetic pathway, de novo synthesis of pyrimidines and protein synthesis (Espín \& Mora, 1978). Mycelium also accumulates glutamine and arginine when deprived either of an amino acid or pyrimidines, in the presence of cycloheximide or at the end of exponential growth. A large proportion of the accumulated arginine is sequestered in an osmotically sensitive compartment (Mora et al., 1978). In this paper, we report the effect of nitrogen deprivation on the accumulation of glutamine and arginine by nongrowing conidia. A positive correlation has been established between this accumulation and the induction of glutamine synthetase as a result of de novo synthesis of this protein. Evidence is also presented regarding the pathway by which the nitrogen of ammonia or glutamine present in the medium is utilized to synthesize and accumulate arginine and/or glutamine. The degradation of glutamine and its subsequent resynthesis by resting cultures has previously been studied with mutants defective in the synthesis of glutamate (Fincham, 1950) or glutamine (Dávila et al., 1978) or by using methionine sulphoximine to inhibit glutamine degradation (Cooper et al., 1976).

\section{METHODS}

Cultures. All stock cultures came from the collection of J. Mora or from Fungal Genetics Stock Center at Humboldt State University Foundation, Arcata, California, U.S.A. The basic strains were: wild-type strain 74-A, the proline auxotrophs prol-3 and prol-4, the tryptophan auxotroph tryp-2, the glutamine auxotrophs $g l n-1 a$ and $g l n-1 b$, the amino nitrogen auxotrophs $a m-1$ and $e n-a m-1$ and the uridine auxotroph $p y r-3 a$. All double or triple mutants were obtained from appropriate crosses of these stocks.

Growth conditions. Conidia obtained as previously reported (Sánchez et al., 1972) were incubated in an aerated culture at $25^{\circ} \mathrm{C}$ in minimal medium $\mathrm{N}(\mathrm{MM})$ of Vogel (1964) supplemented with $1.5 \%$ (w/v) 
sucrose, unless otherwise stated. In some experiments, $\mathrm{NH}_{4} \mathrm{NO}_{3}$ was omitted or replaced by other nitrogen sources as indicated. Crosses were made on $1.7 \%(\mathrm{w} / \mathrm{v})$ corn meal agar (Difco) in the dark at $25^{\circ} \mathrm{C}$.

Determination of glutamic acid, glutamine and arginine pools. Samples for glutamic acid and glutamine analysis were prepared by homogenizing conidia with $80 \%$ (v/v) ethanol. The homogenates were boiled for $10 \mathrm{~min}$, cooled and filtered through membrane filters (Millipore, type RA, $1.2 \mu \mathrm{m}$ ). The filtrates containing the amino acids were lyophilized and the samples were resuspended in deionized water. The amino acids were separated using an Aminco (Silver Springs, Md, U.S.A.) amino acid analyser and quantified in an Aminco Ratio Fluorometer after coupling with $o$-phthaldialdehyde. Under these conditions more than $80 \%$ of the glutamic acid and glutamine were recovered. Arginine was extracted from filtered conidia with $2 \mathrm{ml}$ $5 \%(w / v)$ trichloroacetic acid. After centrifugation, arginine was determined in the supernatant fluid by the method of Van Pilsum et al. (1956).

Ammonia determination. Samples $(10 \mathrm{ml})$ of medium were collected by filtration through membrane filters (Millipore, type HA, $0.45 \mu \mathrm{m}$ ) and, after addition of $0.1 \mathrm{ml} 10 \mathrm{M}-\mathrm{NaOH}$, ammonia was measured in an Orion (Cambridge, Mass, U.S.A.) electrode with a membrane specific for this compound. No interference by glutamine was detected if assays were completed within 10 min of the addition of $\mathrm{NaOH}$.

Glutamine synthetase activity [L-glutamate:ammonia ligase (ADP-forming; EC 6.3.1.2]. Conidia were separated from the culture medium by filtration, washed with water and then acetone, and finally dried under vacuum. All subsequent steps were performed at $4{ }^{\circ} \mathrm{C}$. Acetone powders were ground with dry ice and homogenized in a motor-driven homogenizer with 10 vol. extraction buffer $\left(5 \mathrm{mM}-\mathrm{KH}_{2} \mathrm{PO}_{4}, 50 \mathrm{mM}-\right.$ $\mathrm{K}_{2} \mathrm{SO}_{4}, 0.5 \mathrm{~mm}$-EDTA, $\mathrm{pH} 7 \cdot 2$ ). The preparation was centrifuged for $20 \mathrm{~min}$ at $12000 \mathrm{~g}$ and the extraction procedure was repeated. Transferase activity of glutamine synthetase was measured in the combined supernatants and in the pellet as described by Ferguson \& Sims (1974). Specific activy ( $\mu \mathrm{mol} \gamma$-glutamyl hydroxamate produced $\min ^{-1}$ at $30^{\circ} \mathrm{C}$ ) was calculated by dividing the total activity in the supernatant and the pellet by the total protein of the culture.

Preparation and characterization of anti-glutamine synthetase antibodies. Glutamine synthetase was purified to homogeneity by chromatography on DEAE-cellulose, followed by affinity chromatography on anthranilate-bound Sepharose (Palacios, 1976). Rabbits were immunized and the serum was fractionated with ammonium sulphate to obtain the total $\gamma$-globulin fraction; the specific antibody was further purified by affinity chromatography on a matrix of purified glutamine synthetase bound to Sepharose. Different experimental criteria indicate that this antibody fraction is monospecific for $N$. crassa glutamine synthetase (Palacios et al., 1977). Goat anti-rabbit $\gamma$-globulir was prepared as described by Palacios et al. (1977).

Immunoprecipitation of in vivo-labelled glutamine synthetase. Extracts of conidia labelled in vivo with $\left[{ }^{3} \mathrm{H}\right]$ leucine were incubated in the presence of purified anti-glutamine synthetase antibody followed by addition of anti-rabbit $\gamma$-globulin. To separate the immunoprecipitates, the preparation was centrifuged through a buffer solution containing $20 \%$ (w/v) sucrose (Quinto et al., 1977). The immunoprecipitates were subjected to acrylamide gel electrophoresis in the presence of sodium dodecyl sulphate followed by flucrography as described by Bonner \& Laskey (1974). To measure the relative rates of glutamine synthetase synthesis, ${ }^{3} \mathrm{H}$-labelled conidial extract was mixed with ${ }^{14} \mathrm{C}$-labelled mycelial extract and samples of the mixture were either immunoprecipitated or precipitated with trichloroacetic acid. The samples were then processed for electrophoresis as described above. After fluorography, the gels were cut into $0.5 \mathrm{~cm}$ slices and each slice was counted for ${ }^{3} \mathrm{H} /{ }^{14} \mathrm{C}$ double isotope label in a Packard Tri-Carb model 3390 liquid scintillation spectrometer equipred with a model 544 absolute activity analyser. The ratio ${ }^{3} \mathrm{H} /{ }^{14} \mathrm{C}$ in the immunoprecipitate divided by that of the total protein precipitated indicates the relative rate of enzyme synthesis under both conditions (Quinto et al., 1977).

Protein determination. Samples of conidia were collected on membrane filters (Millipcre, type HA, $0.45 \mu \mathrm{m}$ ) washed with 2 vol. distilled water and placed in $2 \mathrm{ml} 5 \%(\mathrm{w} / \mathrm{v})$ trichloroacetic acid. After centrifugation, the precipitate was resuspended in $1 \mathrm{M}-\mathrm{NaOH}$ and protein was determined by the Lowry method, using bovine serum albumin as standard.

Chemicals. Amino acids, uridine, bovine serum albumin, L-methionine-DL-sulphoximine and $o$-phthaldialdehyde were obtained from Sigma, cycloheximide was from Calbiochem and $\mathrm{L}-\left[4,5-{ }^{3} \mathrm{H}\right]$ leucine and L-[U- $\left.{ }^{14} \mathrm{C}\right]$ leucine were from New England Nuclear.

\section{RESULTS}

\section{Effect of nitrogen deprivation on the accumulation of glutamine and arginine}

When conidia of Neurospora crassa are deprived of certain amino acids in the presence of $\mathrm{NH}_{4} \mathrm{NO}_{3}$, glutamine and arginine accumulate (Espín \& Mora, 1978). The rate of accumulation increased when conidia were nitrogen-starved before amino acid deprivation (Table 1). 
Table 1. Effect of preincubation in nitrogen-free medium on the accumulation of glutamine and arginine by conidia of the prol-3 strain

Conidia with or without $12 \mathrm{~h}$ preincubation in nitrogen-free $\mathrm{MM}$ were incubated in $\mathrm{MM}$ with $\mathrm{NH}_{4} \mathrm{NO}_{3}(25 \mathrm{~mm})$ as nitrogen source.

$\begin{array}{cccc} & & \overbrace{\text { Arginine }} & \text { Glutamine } \\ \text { Culture conditions } & \text { Time }(\mathrm{h}) & 0.032 & 0.068 \\ \text { Not starved } & 0 & 0.290 & 0.530 \\ & 6 & 0.520 & 1.035 \\ \text { Starved } & 12 & 0.015 & 0.031 \\ & 0 & 0.998 & 1.840 \\ & 6 & 1.120 & 3.190\end{array}$

Furthermore, the prol-4 auxotroph accumulated arginine at a rate lower than those shown by other auxotrophs (Espín \& Mora, 1978), but when this strain had been nitrogen-starved, its capacity to accumulate arginine increased (Fig. 1a).

We previously reported that only low concentrations of arginine accumulate in the absence of de novo synthesis of pyrimidines, in the presence of cycloheximide, or in the presence of glycerol as carbon source instead of sucrose (Espín \& Mora, 1978). In the present experiments, arginine accumulation following nitrogen starvation was stimulated in the $p y r-$ $3 a$ uridine auxotroph (Fig. $1 b$ ) and in the prol-3 strain in the presence of cycloheximide (Fig. 1c) or with glycerol as carbon source instead of sucrose (Fig. 1d).

\section{Effects of mutations that impaired ammonia assimilation and/or glutamine synthesis}

The am- 1 strain lacks the activity of the biosynthetic glutamate dehydrogenase (Fincham, 1950) and grows in ammonium as nitrogen source after a lag of $12 \mathrm{~h}$. However, if in addition to the am-1 mutation the en-am-1 mutation is also present, no growth occurs on inorganic nitrogen (unpublished results). No glutamate, glutamine or arginine accumulated when the triple mutant tryp-2 am-1 en-am-1 was incubated with $\mathrm{NH}_{4} \mathrm{NO}_{3}$ after nitrogen deprivation. If glutamine was added instead of $\mathrm{NH}_{4} \mathrm{NO}_{3}$, only this amino acid accumulated. A lack of accumulation of amino acids was expected in the presence of $\mathrm{NH}_{4} \mathrm{NO}_{3}$, but not with glutamine as nitrogen source. This could be explained if ammonia fixation into glutamate is necessary for arginine to accumulate when glutamine is the nitrogen source. The triple mutant excreted ammonia into the medium when glutamine was added after a period of nitrogen deprivation, indicating that this amino acid must be degraded to $\alpha$-ketoglutarate and ammonia for glutamine and arginine to accumulate in the tryp-2 strain. After prolonged incubation, all strains tested excreted some ammonia.

With $\mathrm{NH}_{4} \mathrm{NO}_{3}$ as nitrogen source, the tryp- 2 gln- $1 b$ mutant did not accumulate glutamine; arginine accumulated at a reduced rate and the glutamate concentration increased four to fivefold (Fig. 2a). A similar observation was recorded with glutamine as nitrogen source, except that this amino acid accumulated intracellularly during the first $3 \mathrm{~h}$ of incubation and subsequently disappeared (Fig. $2 b$ ). Nitrogen deprivation before the addition of $\mathrm{NH}_{4} \mathrm{NO}_{3}$ did not affect the accumulation of glutamine and arginine, and again, only the glutamate pool increased (Fig. $2 c$ ). Similar results were observed after addition of glutamine except that glutamine did not accumulate (Fig. 2d). Comparable results were also obtained with the tryp-2 gln-1 $a$ and the prol-4 gln-1a double auxotrophs. This is in contrast to the single tryp-2 mutant which mainly accumulated glutamine and arginine with $\mathrm{NH}_{4} \mathrm{NO}_{3}$ or glutamine as nitrogen source (Fig. $3 a, b$ ). When $\mathrm{NH}_{4} \mathrm{NO}_{3}$ or glutamine was added to conidia of tryp-2 previously deprived of nitrogen, glutamine and arginine accumulated to levels higher than those shown in Fig. 3(a,b); glutamate decreased during starvation and increased on 


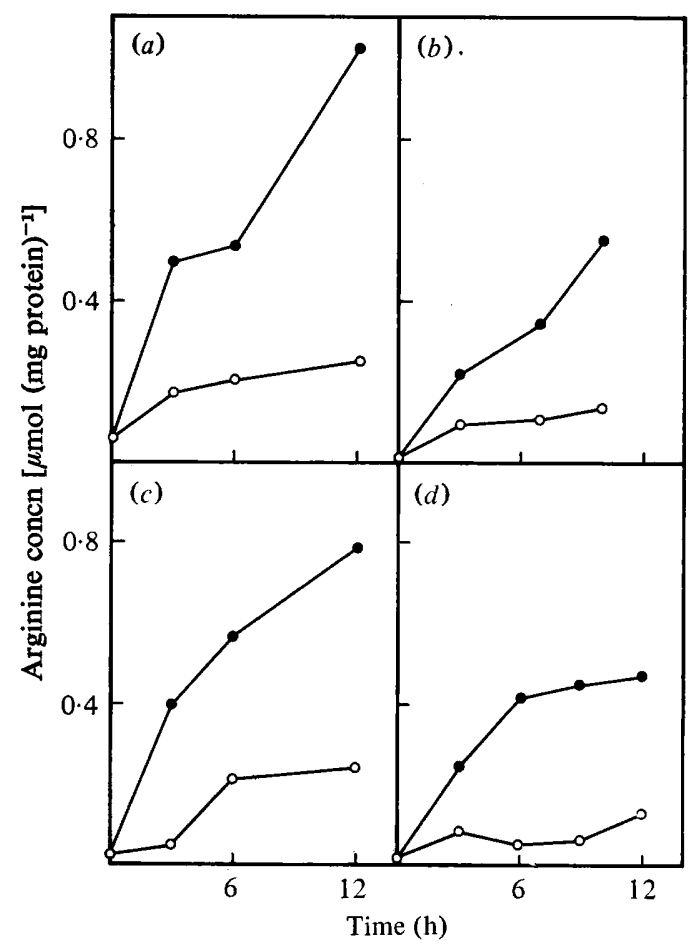

Fig. 1. Effect of nitrogen deprivation on the accumulation of arginine. Conidia were incubated as follows: (a) the prol-4 strain in MM, (b) the pyr-3a strain in MM, (c) the prol-3 strain in $\mathrm{MM}$ in the presence of cycloheximide $\left(10 \mu \mathrm{g} \mathrm{ml}^{-1}\right),(d)$ the prol-3 strain in MM with $2 \%(\mathrm{w} / \mathrm{v})$ glycerol as carbon source, in each case with (O) or without $(O) 12 \mathrm{~h}$ preincubation in nitrogen-free MM (with sucrose as carbon source).

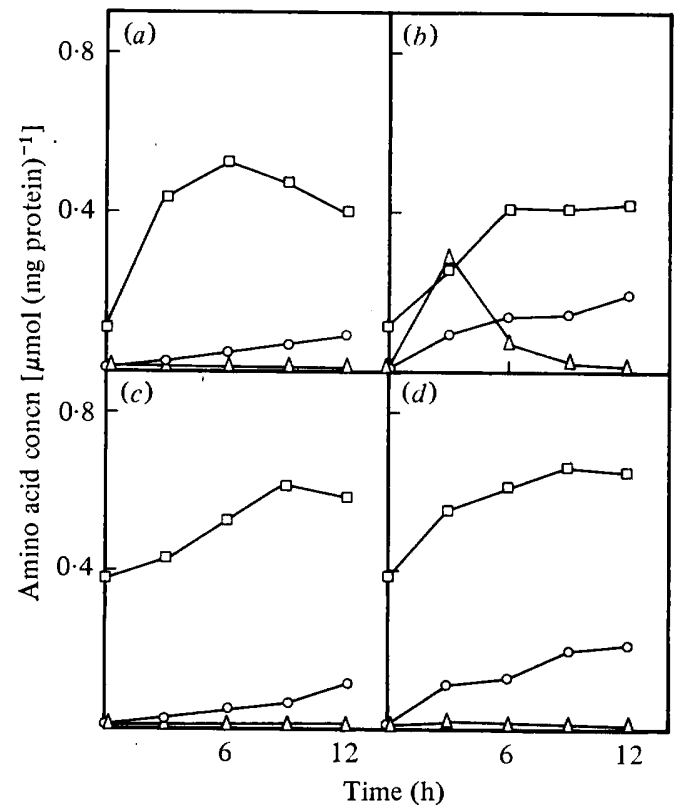

Fig. 2. Accumulation of arginine $(O)$, glutamine $(\triangle)$ and glutamic acid $(\square)$ by conidia of the tryp-2 gln-1b strain incubated in $\mathrm{MM}\left(25 \mathrm{mM}_{-} \mathrm{NH}_{4} \mathrm{NO}_{3}\right)(a, c)$ or with glutamine $\left(100 \mu \mathrm{g} \mathrm{ml}^{-1}\right)$ $(b, d)$, either with $(c, d)$ or without $(a, b) 12 \mathrm{~h}$ preincubation in nitrogen-free medium. 


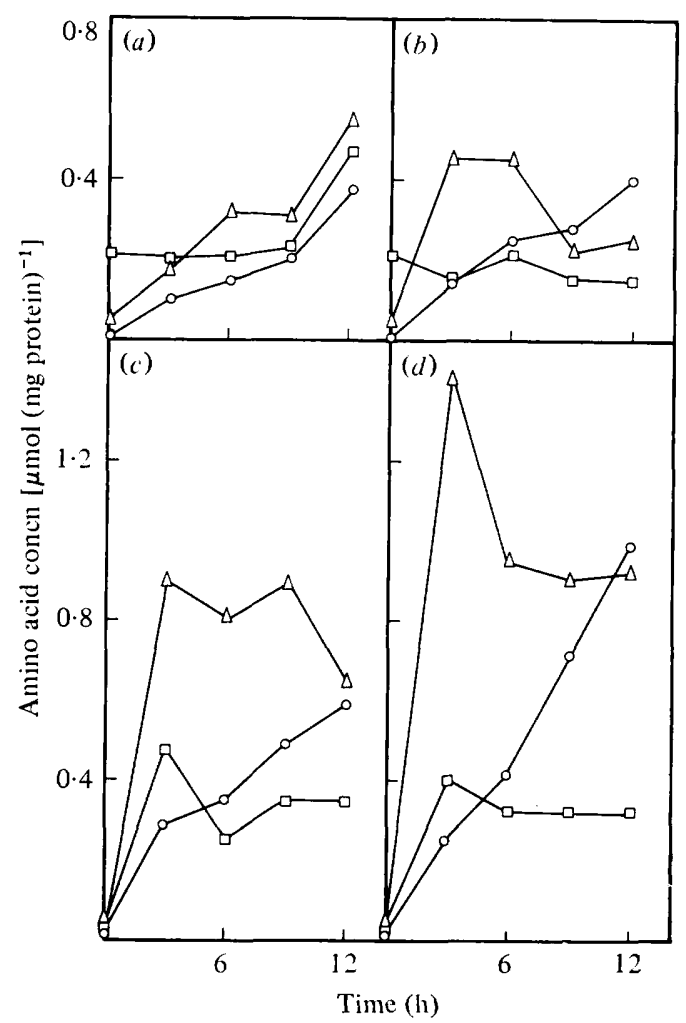

Fig. 3. Accumulation of arginine $(O)$, glutamine $(\triangle)$ and glutamic acid $(\square)$ by conidia of the tryp-2 strain incubated in MM $\left(25 \mathrm{mM}-\mathrm{NH}_{4} \mathrm{NO}_{3}\right)(a, c)$ or with glutamine $\left(100 \mu \mathrm{g} \mathrm{ml}^{-1}\right)(b, d)$, either with $(c, d)$ or without $(a, b) 12 \mathrm{~h}$ preincubation in nitrogen-free medium.

addition of $\mathrm{NH}_{4} \mathrm{NO}_{3}$ or glutamine, reaching within $3 \mathrm{~h}$ concentrations similar to those found in non-deprived cultures (Fig. $3 c, d$ ).

Taken together, these results indicate that in non-growing conidia, glutamine is degraded to $\alpha$-ketoglutarate and ammonium, and that these compounds are in turn converted to glutamic acid and glutamine.

\section{Effect of methionine sulphoximine}

To determine the role of the synthesis and degradation of glutamine in the accumulation of glutamine and arginine by non-growing conidia, the effect of methionine sulphoximine (MS) was studied. This compound is a specific irreversible inhibitor of glutamine synthetase (Ronzio \& Meister, 1968) and also competes with glutamine as a substrate for glutamine transaminase (Cooper et al., 1976). Through the action of the latter enzyme, glutamine is transaminated to $\alpha$-ketoglutaramate which is then hydrolysed to ammonium and $\alpha$-ketoglutarate by an $\omega$-amidase. The occurrence of these enzymes in $N$. crassa has been reported (Monder \& Meister, 1958).

When conidia of the prol-3 strain were incubated in a nitrogen-free medium in the presence of MS, this compound was degraded and glutamine and arginine accumulated (Table 2). This accumulation was observed only after $12 \mathrm{~h}$ incubation and no glutamine synthetase activity was detected during this lag phase. It is probable that this period was required for MS degradation. Similar effects were observed in the presence of MS plus $\mathrm{NH}_{4} \mathrm{NO}_{3}$, but glutamine and arginine accumulated on addition of glutamine plus MS to nitrogen-deprived prol-3 cultures (Fig. 4). 
Table 2. Effect of L-methionine-DL-sulphoximine on amino acid accumulation by the prol-3 strain incubated in nitrogen-free $M M$

\begin{tabular}{lcccc}
\multicolumn{1}{c}{ Culture condition } & Time $(\mathrm{h})$ & $\overbrace{\text { Arginine }}$ Concn $\left[\mu\right.$ mol (mg protein) ${ }^{-1}$ ] & Glutamine & Glutamic acid \\
No addition & 0 & 0.025 & 0.075 & 0.287 \\
& 12 & 0.023 & 0.028 & 0.113 \\
Methionine sulphoximine (5 mM) & 24 & ND & 0.009 & 0.058 \\
& 12 & 0.050 & 0.041 & 0.177 \\
& 24 & 0.290 & 0.261 & 0.146
\end{tabular}

ND, Not detectable.

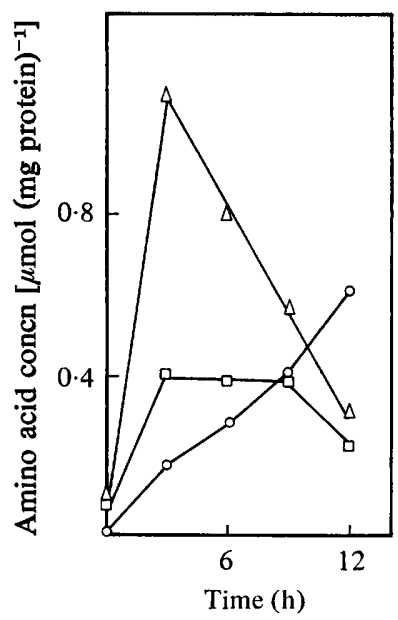

Fig. 4. Effect of L-methionine-DL-sulphoximine on the accumulation of arginine $(O)$, glutamine $(\triangle)$ and glutamic acid $(\square)$. Conidia of the prol-3 strain were incubated in MM without $\mathrm{NH}_{4} \mathrm{NO}_{3}$ but supplemented with glutamine $\left(100 \mu \mathrm{g} \mathrm{ml}^{-1}\right)$ and methionine sulphoximine $(5 \mathrm{mM})$, after $12 \mathrm{~h}$ preincubation in nitrogen-free MM.

As shown above, double mutants lacking glutamine synthetase activity are unable to utilize the nitrogen of glutamine to synthesize and accumulate arginine (Fig. 2). The conversion of glutamine into arginine under conditions in which the activity of glutamine synthetase is completely inhibited (Fig. 4) indicates that MS is being degraded. Because of its competition as a substrate for the transaminase, MS probably spares glutamine for arginine synthesis. The degradation of MS could provide the glutamic acid required for arginine synthesis.

\section{Effect of nitrogen deprivation and the gln-1 mutation on the catabolism of arginine}

We have previously reported that glutamine prevents the catabolism of arginine by repressing arginase synthesis; thus proline auxotrophs will not grow on arginine if glutamine is simultaneously present in the culture medium (Vaca \& Mora, 1977). This glutamine effect was not observed when spores of the prol-4 mutant were deprived of nitrogen before incubation with glutamine and arginine. In the prol-4 gln-1a double mutant, however, the glutamine effect was observed even if the mutant had previously been deprived of nitrogen.

Glutamine synthetase activity

The prol-3 mutant was incubated in medium devoid of proline under conditions in which different amounts of glutamine and arginine accumulated. There was a direct correlation 
Table 3. Intracellular concentrations of glutamine and arginine, and glutamine synthetase activity in conidia of the prol-3 strain under different conditions of incubation

Glutamine synthetase activity is expressed as $\mu \mathrm{mol} \gamma$-glutamyl hydroxamate formed at $30^{\circ} \mathrm{C} \mathrm{min}-1$ $(\mathrm{mg} \text { protein })^{-\mathbf{1}}$.

$\begin{array}{lccc}\text { Condition } & \text { Glutamine } & \begin{array}{c}\text { Arginine } \\ \text { synthetase } \\ \text { activity }\end{array} \\ \text { Not incubated } & 0.068 & 0.032 & 0.004 \\ \text { Incubated } 12 \mathrm{~h} \text { in } \mathrm{MM} & 1.035 & 0.520 & 0.035 \\ \text { Incubated } 12 \mathrm{~h} \text { in } \mathrm{MM} \text { plus cycloheximide } & 0.400 & 0.163 & 0.010 \\ \left(10 \mu \mathrm{g} \mathrm{ml}^{-1}\right) & & & 0.149^{*} \\ \text { Preincubated } 12 \mathrm{~h} \text { in nitrogen-free } \mathrm{MM} \text { and } & 3.190 & 1 \cdot 120 & \\ \text { then } \mathrm{NH}_{4} \mathrm{NO}_{3}(25 \mathrm{mM}) \text { added for additional } & & & \\ 12 \mathrm{~h} & & \\ \text { * Activity was measured after } 12 \mathrm{~h} \text { incubation in nitrogen-free } \mathrm{MM} \text {, just before } \mathrm{NH}_{4} \mathrm{NO}_{3} \text { was added. }\end{array}$

between the quantities of these amino acids accumulating and glutamine synthetase activity (Table 3). Measurements of glutamine synthetase activity in samples taken at intervals during incubation of the prol-3 strain in a nitrogen-free medium showed that it had increased 20 -fold after $9 \mathrm{~h}$. Enzyme induction was partially prevented by adding glutamine as nitrogen source to the culture medium. Results similar to those obtained with the prol-3 auxotroph were found with the tryp-2 auxotroph (results not shown).

\section{De novo synthesis of glutamine synthetase}

To determine whether glutamine synthetase induction was the result of de novo protein synthesis, a pulse of radioactive leucine was given to the prol-3 mutant incubated either with glutamine as nitrogen source or in a nitrogen-free medium. Glutamine synthetase was precipitated with specific antiserum and total proteins with trichloroacetic acid. Figure 5 (A to D) shows the fluorography of total proteins and the specific immunoprecipitates after acrylamide gel electrophoresis in the presence of sodium dodecyl sulphate. The different intensities of the radioactive glutamine synthetase band from the two cultures indicated a positive correlation between the activity of the enzyme and the de novo synthesis of protein; the higher the band intensity, the higher the enzyme specific activity.

To measure the relative rates of enzyme synthesis, double label experiments were performed as described by Quinto et al. (1977). An extract from prol-3 conidia incubated in nitrogen-free medium and labelled with $\left[{ }^{3} \mathrm{H}\right]$ leucine was mixed with an extract from mycelium of the wild-type strain 74-A grown with glutamate as nitrogen source and labelled with $\left[{ }^{14} \mathrm{C}\right]$ leucine. The ${ }^{3} \mathrm{H} /{ }^{14} \mathrm{C}$ ratio in the immunoprecipitate divided by the ${ }^{3} \mathrm{H} /{ }^{14} \mathrm{C}$ ratio of the total protein indicated the relative rate of synthesis of the enzyme in conidia incubated without nitrogen source compared with that in mycelium with glutamate as nitrogen source. Ratios of 0.75 and 1.0 were found in two experiments performed (Fig. 5, E, F) indicating that the relative rates of synthesis of the enzyme were similar under both conditions. Previous experiments have shown that optimal de novo synthesis of the enzyme occurs in $N$. crassa growing on glutamate as nitrogen source (Vichido et al., 1978; Quinto et al., 1977). The ${ }^{3} \mathrm{H} /{ }^{14} \mathrm{C}$ ratio of conidia incubated with glutamine compared with mycelium grown with glutamate was not determined due to the low amount of ${ }^{3} \mathrm{H}$ radioactivity incorporated into glutamine synthetase under the former condition. 

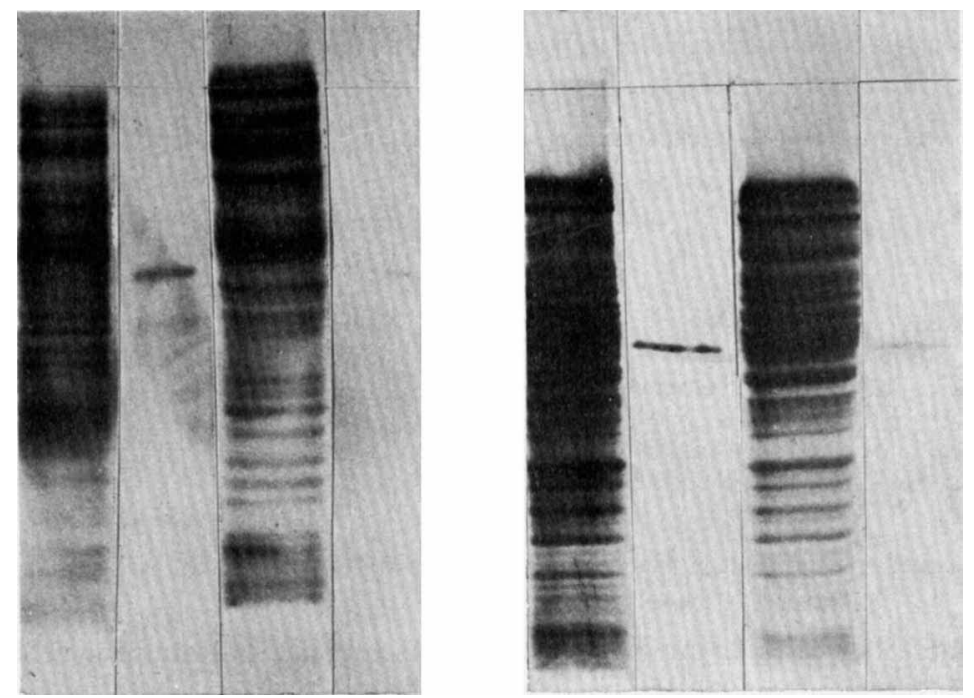

Fig. 5. Conidia of the prol-3 strain were incubated either in nitrogen-free MM or in MM containing $5 \mathrm{~mm}$-glutamine as sole nitrogen source. After $6 \mathrm{~h}$ incubation, a $1 \mathrm{~h}$ pulse of $\left[{ }^{3} \mathrm{H}\right]$ leucine $\left(5 \mu \mathrm{Ci} \mathrm{ml}{ }^{-1}\right)$ was given to each culture and extracts were prepared.

A to $D$. Total protein $(A, C)$ and glutamine synthetase $(B, D)$ were isolated by precipitation with trichloroacetic acid or by specific immunoprecipitation as described in Methods. The samples were then subjected to acrylamide gel electrophoresis and treated for fluorography. Conidia had been incubated in nitrogen-free $\mathbf{M M}$ for $\mathrm{A}$ and $\mathrm{B}$, and in $\mathbf{M M}$ containing glutamine as sole nitrogen source for $\mathrm{C}$ and $\mathrm{D}$.

$\mathrm{E}$ to $\mathrm{H}$. Extracts from either culture were mixed with an extract from 74-A strain grown for $6 \mathrm{~h}$ on MM containing $5 \mathrm{mm-glutamate}$ as sole nitrogen source and pulsed with $\left[{ }^{14} \mathrm{C}\right]$ leucine $\left(0 \cdot 5 \mu \mathrm{Ci} \mathrm{ml} \mathrm{m}^{-1}\right)$, as above. Total protein $(E, G)$ and glutamine synthetase $(F, H)$ from both mixtures were isolated and processed as above. Conidia had been incubated in nitrogen-free $M M$ for $E$ and $F$, and in MM containing glutamine as sole nitrogen source for $\mathrm{G}$ and $\mathrm{H}$.

\section{DISCUSSION}

When conidia of $N$. crassa are deprived of certain amino acids in the presence of $\mathrm{NH}_{4} \mathrm{NO}_{3}$, glutamine and arginine accumulate. Such accumulation was not found in the absence of de novo synthesis of pyrimidines, in the presence of cycloheximide or in the presence of glycerol as carbon source (Espin \& Mora, 1978). The rate of accumulation of glutamine and arginine also increased when ammonia was added to conidia which had been preincubated without a required amino acid or pyrimidine (Table 1 ; Fig. $1 a, b$ ) and this accumulation was no longer prevented by cycloheximide or glycerol as carbon source (Fig. 1c,d).

The increased accumulation of these amino acids was paralleled by an increased specific activity of glutamine synthetase which, in one case at least, involved de novo enzyme synthesis (Table 3, Fig. 5). It is likely, therefore, that the accumulation of glutamine and arginine which occurs when the exponential growth of mycelium stops is also due to an increase in the rate of synthesis of glutamine synthetase (Mora et al., 1978).

Amino acid deprivation in Dictyostelium discoideum also triggers cell aggregation and differentiation (Schindler \& Sussman, 1977).

The presence of mutations that impaired the assimilation of ammonia or the synthesis of glutamine in amino acid-deprived conidia prevented the utilization of the nitrogen atoms of exogenous glutamine for the synthesis and accumulation of arginine (Fig. 2). To explain these effects, we propose that glutamine is first degraded to ammonia and $\alpha$-ketoglutarate which are then sequentially converted to glutamic acid, glutamine and arginine. 


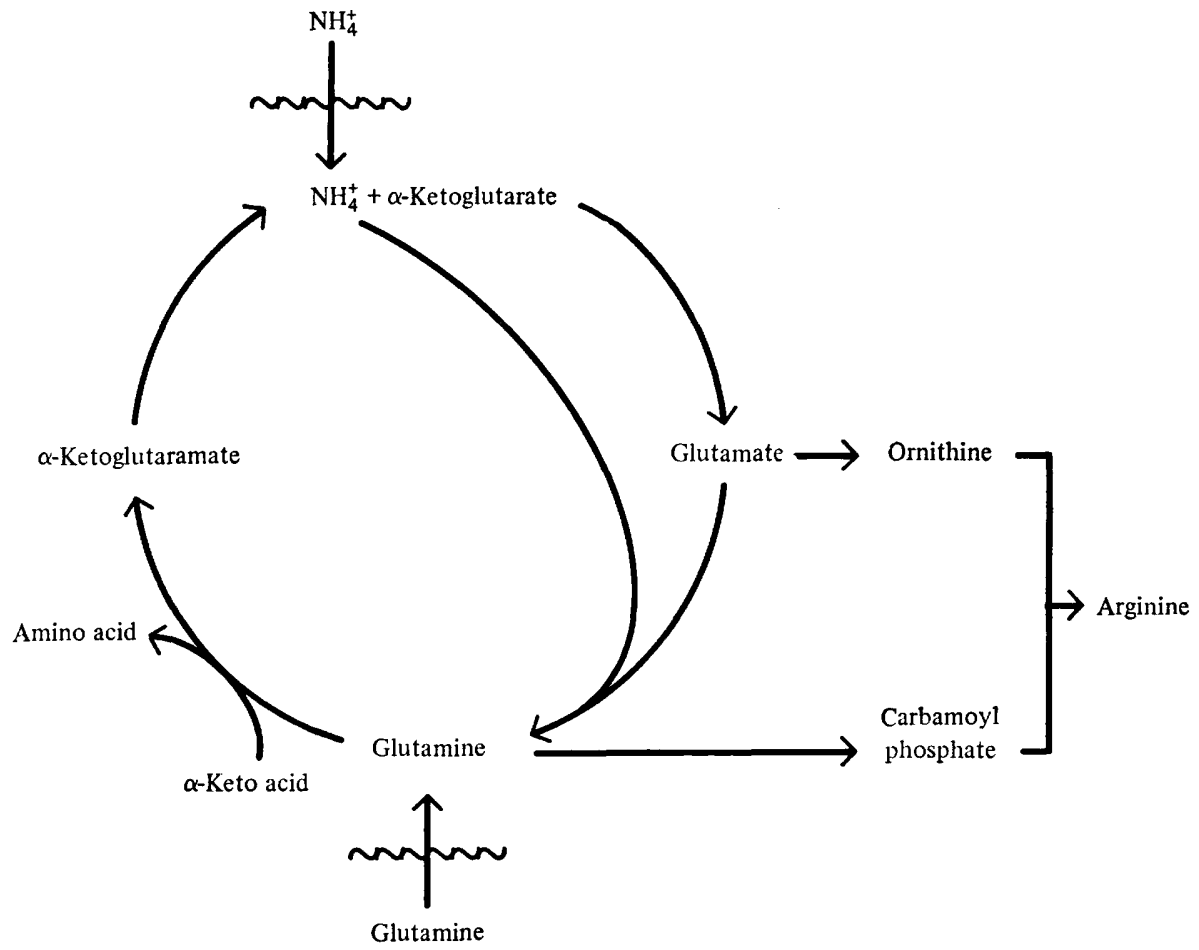

Fig. 6. Schematic diagram of the proposed glutamine cycle.

Evidence for the degradation of glutamine by the $\omega$-amidase pathway in other cell systems has been recently reviewed (Cooper \& Meister, 1977); these enzymes have also been detected in $N$. crassa (Monder \& Meister, 1958). The liberated ammonium ions could be used to resynthesize glutamine through the concerted action of glutamate dehydrogenase and glutamine synthetase.

The above observations can be explained on the basis of a glutamine cycle (Fig. 6), the first step of which is the synthesis of different amino acids through an irreversible transamination, the second is the hydrolysis of $\alpha$-ketoglutaramate to $\alpha$-ketoglutarate and ammonium by an $\omega$-amidase, the third being the formation of glutamic acid and the fourth the resynthesis of glutamine. The accumulation of arginine in the presence of L-methionineDL-sulphoximine and glutamine, when glutamine synthetase is totally inactive, is consistent with the postulated role of glutamine transaminase in the cycle. Alternatively, glutamine might be degraded by the concerted action of an L-amino acid oxidase (Thayer \& Horowitz, 1951) and an $\omega$-amidase to yield ammonia and $\alpha$-ketoglutarate. These, in turn, could lead to glutamine resynthesis. Although the participation of an L-amino acid oxidase could account for glutamine and arginine accumulation, it does not explain why other amino acids accumulate when amino acid-deprived conidia are incubated with either $\mathrm{NH}_{4} \mathrm{NO}_{3}$ (Espín \& Mora, 1978) or glutamine (unpublished results) as the sole nitrogen sources. The requirement for a good carbon source for a variety of amino acids to accumulate is also more consistent with the involvement of a specific glutamine transaminase rather than an L-amino acid oxidase (Espín \& Mora, 1978). Experiments are in progress to determine how glutamine is degraded by amino acid-deprived conidia.

Evidence indicating that the fixation of ammonia into glutamic acid is a necessary step before the transfer of the amide nitrogen of glutamine to arginine is given by the excretion of ammonia by strains that lack the activity of the enzymes that assimilate ammonia into 
glutamic acid. The synthesis of glutamine is also required because $g$ ln auxotrophs are unable to accumulate arginine in the presence of glutamine but accumulate glutamic acid instead (Fig. 2). In contrast to the prol-4 single mutant, the inability of the prol-4 $\mathrm{gln}$ - $1 \mathrm{a}$ strain to grow on arginine plus glutamine after nitrogen deprivation can be explained as the result of degradation of glutamine in the absence of its resynthesis. The proposed cycle would therefore provide a mechanism for non-growing cells to utilize and distribute the carbon and nitrogen from the medium towards the synthesis and accumulation of amino acids, mainly glutamine and arginine.

We are grateful to Dr Fernando Bastarrachea for discussion and his critical review of the manuscript.

\section{REFERENCES}

Bonner, W. M. \& LAskey, R. A. (1974). A film detection method for tritium-labeled proteins and nucleic acids in polyacrylamide gels. European Journal of Biochemistry 46, 83-88.

CoOper, A. J. \& Meister, A. (1977). The glutamine transaminase- $\omega$-amidase pathway. CRC Critical Reviews in Biochemistry 4, 281-303.

Cooper, A. J., Stephani, R. A. \& Meister, A. (1976). Enzymatic reactions with methionine sulfoximine. Conversion to the corresponding $\alpha$-imino and $\alpha$-keto acids and to $\alpha$-ketobutyrate and methane sulfinimide. Jorsnal of Biological Chemistry 251, 6674-6682.

Dávila, G., Sánchez, F., Palacios, R. \& Mora, J. (1978). Genetics and physiology of Neurospora crassa glutamine auxotrophs. Journal of Bacterio$\log y$ 134, 693-698.

Espín, G. \& MoRA, J. (1978). Effect of the deprivation of amino acids on conidia of Neurospora crassa. Journal of General Microbiology 104, 233-240.

Ferguson, A. R. \& SimS, A. P. (1974). The regulation of glutamine metabolism in Candida utilis: the inactivation of glutamine synthetase. Journal of General Microbiology 80, 173-185.

FinchAM, J. R. S. (1950). Mutant strains of Neurospora deficient in aminating ability. Journal of Biological Chemistry 182, 61-73.

MONDER, C. \& MeIsTer, A. (1958). $\alpha$-Ketoglutaramic acid as a product of enzymic transamination of glutamine in Neurospora. Biochimica et biophysica acta 28, 202-203.

MORA, Y., EsPín, G., WillMS, K. \& MORA, J. (1978). Nitrogen accumulation in mycelium of Neurospora crassa. Journal of General Microbiology 104, 241-250.

Palacios, R. (1976). Neurospora crassa glutamine synthetase. Purification by affinity chromatography and characterization of subunit structure. Journal of Biological Chemistry 251, 4787-4791.

Palacios, R., Campomanes, M. \& Quinto, C.
(1977). Neurospora crassa glutamine synthetase. Translation of specific messenger ribonucleic acid in a cell-free system derived from rabbit reticulocytes. Journal of Biological Chemistry 252, 30283034.

Quinto, C., Mora, J. \& Palacios, R. (1977). Neurospora crassa glutamine synthetase. Role of enzyme synthesis and degradation during exponential growth. Journal of Biological Chemistry 252, 8724-8727.

Ronzio, R. A. \& Meister, A. (1968). Phosphorylation of methionine sulfoximine by glutamine synthetase. Proceedings of the National Academy of Sciences of the United States of America 59, $164-170$.

Sánchez, S., Martínez, L. \& Mora, J. (1972). Interactions between amino acid transport systems in Neurospora crassa. Journal of Bacterio$\log y$ 112, 276-284.

SCHINDleR, J. \& Sussman, M. (1977). Ammonia determines the choice of morphogenic pathways in Dictyostelium discoideum. Journal of Molecular Biology 116, 161-169.

THAYER, S. P. \& Horowitz, N. H. (1951). The L-amino acid oxidase of Neurospora. Journal of Biological Chemistry 192, 755-767.

VACA, G. \& MoRA, J. (1977). Nitrogen regulation of arginase in Neurospora crassa. Journal of Bacterio$\log y$ 131, 719-725.

Van Pilsum, J. F., Martin, R. P., Kito, E. \& Hess, J. (1956). Determination of creatine, creatinine, arginine, guanido-acetic acid, guanidine and methyl-guanidine in biological fluids. Journal of Biological Chemistry 222, 225-236.

Vichido, I., Mora, Y., QUiNTo, C., Palacios, R. \& MORA, J. (1978). Nitrogen regulation of glutamine synthetase in Neurospora crassa. Journal of General Microbiology 106, 251-259.

VoGEL, H. J. (1964). Distribution of lysine pathways among fungi: evolutionary implications. American Naturalist 98, 435-446. 